\title{
The Association between NOS3 Gene Polymorphisms and Hypoxic-Ischemic Encephalopathy Susceptibility and Symptoms in Chinese Han Population
}

\author{
Yongqin Wu, ${ }^{1}$ Zhiling Zhu, ${ }^{1}$ Xiaoxia Fang, ${ }^{1}$ Ling Yin, ${ }^{2}$ Yuxia Liu, ${ }^{2}$ \\ Shouxia $\mathrm{Xu}^{1}{ }^{1}$ and Aixue $\mathrm{Li}^{3}$ \\ ${ }^{1}$ Department of Nursing, Xinxiang Central Hospital, Affiliated Central Hospital, Xinxiang Medical University, No. 56, \\ Jinsui Road, Xinxiang 453000, China \\ ${ }^{2}$ Department of Pediatrics, Xinxiang Central Hospital, Affiliated Central Hospital, Xinxiang Medical University, No. 56, \\ Jinsui Road, Xinxiang 453000, China \\ ${ }^{3}$ Department of Pediatric Rehabilitation, Xinxiang Central Hospital, Affiliated Central Hospital, Xinxiang Medical University, No. 56, \\ Jinsui Road, Xinxiang 453000, China \\ Correspondence should be addressed to Zhiling Zhu; zhilxxch@163.com
}

Received 18 August 2016; Revised 9 November 2016; Accepted 27 November 2016

Academic Editor: Cristiano Capurso

Copyright (C) 2016 Yongqin Wu et al. This is an open access article distributed under the Creative Commons Attribution License, which permits unrestricted use, distribution, and reproduction in any medium, provided the original work is properly cited.

\begin{abstract}
Endothelial NOS (NOS3) has a potential role in the prevention of neuronal injury in hypoxic-ischemic encephalopathy (HIE). Thus, we aimed to explore the association between NOS3 gene polymorphisms and HIE susceptibility and symptoms in a Chinese Han population. Three single nucleotide polymorphisms (SNPs) in the NOS3 gene, rs1800783, rs1800779, and rs2070744, were detected in 226 children with HIE and 212 healthy children in a Chinese Han population. Apgar scores and magnetic resonance image scans were used to estimate the symptoms and brain damage. The association analyses were conducted by using SNPStats and SPSS 18.0 software. The genotype and allele distributions of rs1800779 and rs1799983 displayed no significant differences between the patients and the controls, while the rs 2070744 allele distribution was significantly different (corrected $P=0.009$ ). For clinical characteristics, the rs2070744 genotype distribution was significantly different in patients with different Apgar scores $(\leq 5$, TT/TC/CC $=6 / 7 / 5 ; 6 \sim 7$, $\mathrm{TT} / \mathrm{TC} / \mathrm{CC}=17 / 0 / 0 ; 8 \sim 9, \mathrm{TT} / \mathrm{TC} / \mathrm{CC}=6 / 2 / 0 ; 10, \mathrm{TT} / \mathrm{TC} / \mathrm{CC}=7 / 1 / 0 ;$ corrected $P=0.006)$ in the 1001 to $1449 \mathrm{~g}$ birth weight subgroup. The haplotype test did not show any associations with the risk and clinical characteristics of HIE. The results suggest that NOS3 gene SNP rs2070744 was significantly associated with HIE susceptibility and symptom expression in Chinese Han population.
\end{abstract}

\section{Introduction}

Neonatal hypoxic-ischemic encephalopathy (HIE), a common cause of neurological deficits in adulthood, can lead to severe brain damage through cerebral hypoxia or ischemia during the perinatal period in infants [1]. HIE mostly occurs in full-term children but may also be observed in preterm children due to the nuchal cord, amniotic fluid abnormalities, asphyxia during birth, and so forth [2]. Symptoms of neonatal HIE include fetal distress and decreased Apgar scores after birth, and a large portion of patients with HIE also have serious long-term side-effects, such as cerebral palsy, epilepsy, and learning difficulties $[3,4]$. HIE has an incidence of approximately $0.60 \%$ worldwide and $0.92 \%$ in China and brings heavy financial burdens for society and both financial and psychological pressures for a patient's family [5].

It is known that the atherosclerosis of intracranial arteries is responsible for most ischemic events in the brain [6]. But the intracellular content of antioxidants, such as glutathione peroxidase and manganese-superoxide dismutase, has significantly higher activation in the brain arteries of premature human fetuses [7]. So the extensive antioxidant defenses may have the ability to protect the brain arteries and prevent ischemic events in the newborn [6]. However, another important pathophysiology of HIE refers to the disrupted integrity of blood-brain barrier (BBB), which is a physical and 
metabolic barrier that separates the peripheral circulation from the central nervous system and serves to regulate and protect the microenvironment of the brain [8]. The integral $\mathrm{BBB}$ could reduce the permeability to large proteins such as low-density lipoprotein (LDL) and then block uptake of the plasma LDL by endothelial cells of brain arteries [7, 9]. However, the disruption of $\mathrm{BBB}$ in hypoxic-ischemic conditions is multifactorial and may involve factors such as oxidative stress, enhanced production of vascular endothelial growth factor (VEGF), inflammatory cytokines, and nitric oxide (NO) [10].

$\mathrm{NO}$ is synthesized by the nitric oxide synthase (NOS) enzyme family through sequential oxidation steps that convert the amino acid L-arginine to L-citrulline and plays both neurodegenerative and neuroprotective roles for neuronal cells [11]. There are three different forms of NOS, of which the first two isoforms, neuronal NOS (nNOS or NOS1) and inducible NOS (iNOS or NOS2), mediate early and late neurotoxic effects, respectively [12]. However, endothelial NOS (eNOS or NOS3) is predominantly expressed in vascular endothelial cells and can prevent neuronal injury by producing small amounts of NO to expand blood vessels, maintain cerebral blood, inhibit platelet aggregation and relaxation, or prevent oxidative damage $[11,13]$.

The human NOS3 gene, which is located at 7q35-36, has a genomic size of $21 \mathrm{~kb}$, is composed of 26 exons, and encodes a $135 \mathrm{kDa}$ functional homodimer [14]. Several allelic variations in the NOS3 gene open reading frames, introns, and promoter regions have been identified for possible association with human diseases' susceptibility, including cardiovascular disease [15], Alzheimer disease [16], and a variety of carcinomas $[17,18]$. Kuzmanić Šamija et al. $[19,20]$ have described potential associations between NOS3 gene polymorphisms and HIE susceptibility. The single nucleotide polymorphism (SNP) rs1808593 and the TGT haplotype, which consists of rs1800783, rs1800779, and rs2070744, may also associate with HIE susceptibility [19], while the rs1808593 TT genotype may associate with medium to severe brain damage [20]. However, the association between NOS3 gene polymorphisms and its disease susceptibility and symptom expression in other populations has not been fully understood.

In the present study, we hypothesized that NOS3 gene polymorphisms might associate with the susceptibility and a variety of clinical characteristics of HIE in a Chinese Han population. A case-control study was conducted between children born full-term with HIE and a group of healthy individuals (control group) matched for gender, gestation week, and birth weight. Two SNPs in the promoter (rs1800779 and rs2070744) and the most commonly investigated NOS gene tagging SNP (rs1799983) were selected for association analysis via high quality gene amplifications. We found that SNP rs2070744 in the NOS3 gene may be significantly associated with HIE susceptibility and Apgar scores.

\section{Materials and Methods}

2.1. Participants. Two hundred and twenty-six unrelated children born full-term (122 males and 104 females) with HIE (patient group) were recruited for the HIE group. Two hundred and twelve healthy children born full-term (119 males and 93 females) without any neurological diseases were also recruited as the control group. All of the participants were admitted to the Xinxiang Central Hospital between January 2008 and July 2013. Patients with HIE were diagnosed in accordance with at least one of the following criteria: (1) fetal heart rate during delivery $<100$ or $>160$ times/min; or (2) Apgar score $\leq 3$ at $1 \mathrm{~min}$ and $\leq 5$ at $5 \mathrm{~min}$ or arterial $\mathrm{pH}$ $\leq 7.00$; or (3) children that had neurological symptoms shortly after birth, which continued for more than $24 \mathrm{~h}$ [21]. However, patients with inborn inherited metabolic diseases and whose mothers had intrauterine infections or a smoking history during pregnancy were excluded. The patients with HIE were diagnosed and classified with the grade of hypoxic-ischemic brain damage (slight, moderate, and severe) by magnetic resonance imaging (MRI) at two years of age $[20,22,23]$.

The demographics and clinical characteristics of the participants with their mother were detailed in Table 1. All of the parents of the participants consented to participate in the study after reviewing the informed consent. All procedures performed in studies involving human participants were in accordance with the ethical standards of the Xinxiang Central Hospital and with the 1964 Helsinki Declaration and its later amendments or comparable ethical standards.

2.2. DNA Extraction and Genotyping. The global genomic DNAs were extracted from peripheral blood mononuclear cells using standard protocols and then stored at $-20^{\circ} \mathrm{C}$. Two SNPs in the promoter (rs1800779 and rs2070744) and the most commonly investigated tagging SNP (rs1799983) in the NOS3 gene were selected and amplified by polymerase chain reaction (PCR) with the primers shown in Table 2. The PCR amplification was performed in a $25 \mu \mathrm{L}$ reaction volume containing $2.5 \mu \mathrm{L} 10 \times$ PCR buffer, $0.5 \mu \mathrm{L}$ dNTP mix $(2.5 \mathrm{mM})$, $1 \mu \mathrm{L}$ of each primer $(10 \mu \mathrm{M}), 1 \mu \mathrm{L}$ genomic DNA, $0.4 \mu \mathrm{L}$ Taq DNA polymerase ( $5 \mathrm{U} / \mu \mathrm{L}$, supplied by Tian Gen), and $18.6 \mu \mathrm{L}$ sterile deionized water. The following PCR conditions were used for amplification: (1) initial denaturation at $94^{\circ} \mathrm{C}$ for $5 \mathrm{~min}$; (2) 35 cycles of $94^{\circ} \mathrm{C}$ for $30 \mathrm{~s}, 65^{\circ} \mathrm{C}$ (rs1800779), $63^{\circ} \mathrm{C}$ (rs2070744), or $60^{\circ} \mathrm{C}$ (rs1799983) for $30 \mathrm{~s}$, and $72^{\circ} \mathrm{C}$ for $45 \mathrm{~s}$; and (3) final elongation at $72^{\circ} \mathrm{C}$ for $10 \mathrm{~min}$. The PCR products were separated on $1.5 \%$ agarose gels, and the fragments were extracted with a TIANgel Midi Purification Kit (supplied by Tian Gen). The purified PCR products were sequenced using the same primers on an Applied Biosystems 3730xl DNA Sequencer.

2.3. Statistical Analysis. The Hardy-Weinberg equilibrium (HWE) was determined using Haploview 4.1 to examine the genotype distributions of the three SNPs in the NOS3 gene and establish whether or not the given sample comes from a normally distributed population. The strength of the linkage disequilibrium between the three SNPs was determined using $D^{\prime}$ and $r^{2}$ algorithm testing with the SHEsis online software (http://analysis.bio-X.cn/myAnalysis.php) [24]. The differences in the genotypic and allelic frequency distributions between the patients with HIE and the control group were estimated with the SPSS software 18.0 using the Pearson chi-square $\left(\chi^{2}\right)$ test. Haplotype analysis for 
TABLE 1: Demographic and clinical characteristics of the participants with their mother.

\begin{tabular}{|c|c|c|c|c|}
\hline Characteristics & Patients & Controls & $t / \chi^{2}$ & $P$ \\
\hline \multicolumn{5}{|l|}{ Children } \\
\hline Sample size $(N)$ & 226 & 212 & & \\
\hline \multicolumn{5}{|l|}{ Gender $(N)$} \\
\hline Male & 122 & 119 & 0.204 & 0.701 \\
\hline Female & 104 & 93 & & \\
\hline Gestation week (weeks) & $38.30 \pm 0.96$ & $38.36 \pm 1.19$ & 0.558 & 0.577 \\
\hline \multicolumn{5}{|l|}{ Birth weight $(N)$} \\
\hline$\leq 1000 \mathrm{~g}$ & 6 & 3 & 7.488 & 0.058 \\
\hline $1001 \sim 1499 \mathrm{~g}$ & 51 & 40 & & \\
\hline $1500 \sim 2499 \mathrm{~g}$ & 117 & 96 & & \\
\hline$\geq 2500 \mathrm{~g}$ & 52 & 73 & & \\
\hline \multicolumn{5}{|l|}{ Apgar score $(N)$} \\
\hline$\leq 5$ & 72 & 49 & 16.404 & 0.001 \\
\hline $6 \sim 7$ & 65 & 51 & & \\
\hline $8 \sim 9$ & 49 & 39 & & \\
\hline 10 & 40 & 73 & & \\
\hline \multicolumn{5}{|l|}{ Grade $(N)$} \\
\hline Slightly & 101 & & & \\
\hline Moderately & 97 & & & \\
\hline Severely & 26 & & & \\
\hline \multicolumn{5}{|l|}{ Their mother } \\
\hline Sample size $(N)$ & 208 & 200 & & \\
\hline Age (years) & $26.32 \pm 2.19$ & $26.19 \pm 2.05$ & -0.615 & 0.538 \\
\hline Antepartum weight $(\mathrm{Kg})$ & $57.73 \pm 7.28$ & $58.41 \pm 7.64$ & 0.916 & 0.360 \\
\hline \multicolumn{5}{|l|}{ Complications (\%) } \\
\hline Hypertension & 6.4 & 5.9 & 0.011 & 0.916 \\
\hline Heart disease & 2.6 & 2.0 & 0.077 & 0.781 \\
\hline Diabetes mellitus & 8.6 & 6.9 & 0.386 & 0.534 \\
\hline Anemia & 9.7 & 10.3 & 0.088 & 0.766 \\
\hline \multicolumn{5}{|l|}{ Factors in parturient } \\
\hline Conception times of parturient (times) & $1.22 \pm 0.10$ & $1.21 \pm 0.09$ & -1.056 & 0.292 \\
\hline Amniotic fluid volume (L) & $1.02 \pm 0.08$ & $1.03 \pm 0.09$ & 1.181 & 0.238 \\
\hline Amniotic fluid pollution (\%) & 19.4 & 13.7 & 2.262 & 0.133 \\
\hline Umbilical cord around the neck (\%) & 17.4 & 16.9 & 0.007 & 0.934 \\
\hline Premature rupture of membranes (\%) & 2.4 & 1.8 & 0.077 & 0.781 \\
\hline
\end{tabular}

TABLE 2: Primers for PCR.

\begin{tabular}{ll}
\hline dbSNP ID & Primers $\left(5^{\prime} \sim 3^{\prime}\right)$ \\
\hline \multirow{2}{*}{ rs1800779 } & F: TCTGCCTCTCCCAGTCTCTCA \\
& R: AGCACTCTCCAGGCACTTCAG \\
rs2070744 & F: GACACAGAACTACAAACCCC \\
& R: GCAGGTCAGCAGAGAGACTA \\
rs1799983 & F: GCTCAGCCCCAGAACCCCCT \\
& R: GCTCCAGGGGCACCTCAAGG \\
\hline
\end{tabular}

the NOS3 gene was performed using the online SNPStats software (http://bioinfo.iconcologia.net/snpstats) [25]. The associations between the SNPs in the NOS3 gene and the clinical characteristics were also analyzed with SPSS 18.0 using the $\chi^{2}$ test. To control for possible confounding effects by gender, birth weight, and gestation week, sample stratification was repeated with these factors. Bonferroni correction was applied to avoid a type I error in the multiple tests [26]. The Genetic Power Calculator was used for the power analysis [27]. All of the statistical analyses were two-tailed, and the level of statistical significance was adjusted to $P<0.05$.

\section{Results}

3.1. Association between the SNPs and HIE Susceptibility. The rs1800779 genotype distribution in the patients and controls fit HWE, while rs2070744 and rs1799983 slightly deviated from HWE in patients with HIE $(P<0.05$, Table 3$)$. The genotype and allele distributions of rs1800779 and rs1799983 displayed no significant differences when comparing the patients with HIE and the controls $(P>0.05$, Table 3$)$. For 
TABLE 3: Association of NOS3 gene polymorphisms with the risk of HIE.

\begin{tabular}{|c|c|c|c|c|c|c|c|c|c|c|c|c|}
\hline \multirow{2}{*}{ dbSNP ID } & \multicolumn{5}{|c|}{ Patients $(N=226)$} & \multicolumn{5}{|c|}{ Controls $(N=212)$} & \multicolumn{2}{|c|}{$P$ value } \\
\hline & $\operatorname{HWE}(P)$ & & Genotyl & & MAF & $\operatorname{HWE}(P)$ & & enoty & & MAF & Genotype & Allele \\
\hline \multirow{2}{*}{ rs1800779 } & & GG & GA & AA & & & GG & GA & AA & & & \\
\hline & 0.24 & 4 & 36 & 186 & 0.02 & 0.42 & 3 & 35 & 174 & 0.01 & 0.947 & 0.974 \\
\hline \multirow{2}{*}{ rs2070744 } & & $\mathrm{TT}$ & TC & $\mathrm{CC}$ & & & $\mathrm{TT}$ & $\mathrm{TC}$ & $\mathrm{CC}$ & & & \\
\hline & $<0.05$ & 170 & 43 & 13 & 0.06 & 0.06 & 179 & 29 & 4 & 0.02 & 0.026 & 0.003 \\
\hline \multirow{2}{*}{ rs1799983 } & & $\mathrm{TT}$ & TG & GG & & & $\mathrm{TT}$ & TG & GG & & & \\
\hline & $<0.05$ & 22 & 47 & 157 & 0.10 & 0.06 & 13 & 59 & 140 & 0.06 & 0.122 & 0.975 \\
\hline
\end{tabular}

TABLE 4: Association of the haplotypes with the risk of HIE.

\begin{tabular}{|c|c|c|c|c|c|c|}
\hline \multirow{2}{*}{ dbSNP ID } & \multirow{2}{*}{ Haplotype } & \multicolumn{2}{|c|}{ Frequencies } & \multirow{2}{*}{ OR } & \multirow{2}{*}{$95 \%$ CI } & \multirow{2}{*}{$P$ value } \\
\hline & & Patients & Controls & & & \\
\hline \multirow{4}{*}{ rs1800779-rs2070744 } & $\mathrm{AT}$ & 0.7671 & 0.8197 & 1.00 & Ref. & - \\
\hline & $\mathrm{AC}$ & 0.1355 & 0.0836 & 0.65 & $0.43-0.99$ & 0.045 \\
\hline & GT & 0.0802 & 0.0930 & 1.09 & $0.68-1.76$ & 0.713 \\
\hline & GC & 0.0171 & 0.0037 & 0.22 & $0.03-1.69$ & 0.154 \\
\hline \multirow{4}{*}{ rs2070744-rs1799983 } & TG & 0.6847 & 0.7332 & 1.00 & Ref. & - \\
\hline & $\mathrm{TT}$ & 0.1627 & 0.1805 & 1.03 & $0.74-1.43$ & 0.861 \\
\hline & CG & 0.1140 & 0.0673 & 0.61 & $0.38-0.99$ & 0.046 \\
\hline & $\mathrm{CT}$ & 0.0386 & 0.0200 & 0.55 & $0.22-1.38$ & 0.203 \\
\hline \multirow{4}{*}{ rs1800779-rs1799983 } & AG & 0.7282 & 0.7231 & 1.00 & Ref. & - \\
\hline & $\mathrm{AT}$ & 0.1745 & 0.1803 & 1.04 & $0.75-1.45$ & 0.823 \\
\hline & GG & 0.0705 & 0.0765 & 1.10 & $0.65-1.89$ & 0.717 \\
\hline & GT & 0.0269 & 0.0202 & 0.76 & $0.30-1.96$ & 0.565 \\
\hline
\end{tabular}

rs2070744, nominal differences were found in the genotype $\left(\chi^{2}=7.279, P=0.026\right.$, Table 3$)$ and allele $\left(\chi^{2}=8.795, P=\right.$ 0.003 , Table 3 ) distributions when comparing the patients with the controls. However, after the $P$ values were adjusted by Bonferroni correction, only the rs2070744 allele distribution remained significant (corrected $P=0.009$ ). Patients with HIE had a 1.6-fold higher C allele frequency in rs2070744 than in the controls. The study had an overall power of 0.792 .

3.2. Association between the Haplotypes and HIE Susceptibility. No obvious linkage disequilibrium was found among rs1800779, rs2070744, and rs1799983 in patients with HIE, though a modest linkage disequilibrium was observed between rs1800779 and rs2070744 in controls $\left(D^{\prime}=0.564\right.$, $r^{2}=0.003$, Figure 1). In haplotype analysis, rs1800779rs2070744 AC $(\mathrm{OR}=0.65,95 \%$ CI: $0.43-0.99, P=0.045$, Table 4) and rs2070744-rs1799983 CG (OR = 0.61, 95\% CI: $0.38-0.99, P=0.046$, Table 4 ) haplotypes had significantly higher frequencies in patients with HIE than in controls. However, the differences were not significant after Bonferroni corrections. No haplotypes with these three SNPs were found to associate with HIE susceptibility $(P>0.05$, data not shown).

3.3. Association between the SNPs and the Symptoms of HIE. No association was found between the three SNPs (rs1800779, rs2070744, and rs1799983) and the clinical symptoms (Apgar score and the grade of brain injury) in patients with HIE
$(P>0.05)$. However, when patients were stratified by birth weight, the rs2070744 genotype distribution was significantly different in the patients of 1001 to $1499 \mathrm{~g}$ subgroup with different Apgar scores $(\leq 5, \mathrm{TT} / \mathrm{TC} / \mathrm{CC}=6 / 7 / 5 ; 6 \sim 7$, $\mathrm{TT} / \mathrm{TC} / \mathrm{CC}=17 / 0 / 0 ; 8 \sim 9, \mathrm{TT} / \mathrm{TC} / \mathrm{CC}=6 / 2 / 0 ; 10, \mathrm{TT} / \mathrm{TC} / \mathrm{CC}$ $\left.=7 / 1 / 0 ; \chi^{2}=22.206, P=0.001\right)$ and grades of brain injury (slightly, TT/TC/CC $=16 / 4 / 1$; moderately, TT/TC/CC $=17 / 5 / 1 ;$ severely, TT/TC $/ \mathrm{CC}=3 / 1 / 3 ; \chi^{2}=10.093, P=$ 0.039). When stratified by gender, the rs1799983 genotype distribution was significantly different in female patients with different grades of brain injury (slightly, TT/TG/GG = 8/8/36; moderately, TT/TG/GG = 4/4/32; severely, $\mathrm{TT} / \mathrm{TG} / \mathrm{GG}=$ $\left.0 / 6 / 6 ; \chi^{2}=14.554, P=0.024\right)$. Furthermore, when stratified by gestation week, the rs1799983 genotype distribution was significantly different in patients of 37 weeks with different grades of brain injury (slightly, TT/TG/GG $=3 / 1 / 4$; moderately, TT/TG/GG = 3/1/17; severely, TT/TG/GG=0/4/8; $\chi^{2}=$ 9.731, $P=0.045)$. However, after the $P$ values were adjusted by Bonferroni correction, only the association between the rs2070744 genotype and Apgar score in patients with a birth weight between 1001 and $1499 \mathrm{~g}$ was significant (corrected $P=0.006)$.

\section{Discussion}

In the present study, we focused on NOS3 and investigated its association with HIE susceptibility and symptom expression in a Chinese Han population. We first determined that 


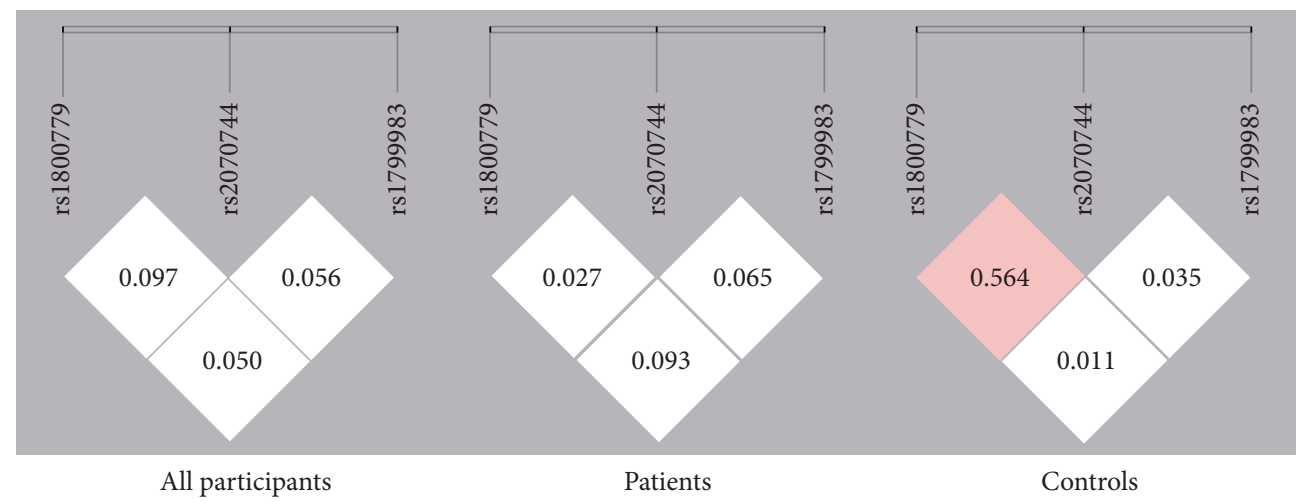

FIGURE 1: The linkage disequilibrium among the three NOS3 gene SNPs. The numbers in the squares represent the $D^{\prime}$ values for linkage disequilibrium.

the SNP rs2070744 in the NOS3 gene was associated with HIE susceptibility, while rs1800779 and rs1799983 were not. Furthermore, in our samples, no haplotypes were associated with HIE susceptibility. Finally, by analyzing subgroup clinical characteristics, the association between the rs2070744 genotype and Apgar scores in patients with a birth weight between 1001 and $1499 \mathrm{~g}$ was significant.

These results are partially consistent with studies in a European population $[19,20]$. The associations between the NOS3 gene variants and the susceptibility and/or clinical contributors were obvious. The rs2070744, which is located in the NOS3 gene promoter, was an interesting variant in our study, though other tagging SNPs or haplotypes in that gene were prevalent in a European population. This difference may be due to the distinct populations with different genetic backgrounds and the sample sizes. Indeed, the susceptibility to disease and the SNP genotype distributions in the NOS3 gene were different in Chinese and European populations (data from the International HapMap Project).

Several recently published articles have also employed a "candidate gene" approach and have demonstrated that the promoter region and tagging SNPs in the NOS3 gene were related to the susceptibility of cardiovascular disorders, such as hypertension [28], coronary artery disease [29], and heart failure [30]. The potential mechanisms of these associations, including changes in eNOS enzyme localization, activity, or expression, might be related to changes in the susceptibility to cardiovascular disease. The promoter SNP rs2070744 (Thr786Cys) was one of the most interesting variants in the NOS3 gene, which has been identified to associate with cardiovascular disorders in Japanese as well as Caucasian populations [31, 32]. The $\mathrm{C} / \mathrm{C}$ genotype and $\mathrm{C}$ allele appear to be risk factor for an increasing incidence in these cardiovascular disorders.

In HIE, hypoxic and ischemic effects caused encephalopathy and may have similar pathophysiological effects on the systemic circulation. When hypoxia-ischemia occurred in the cerebrum, NOS3 was activated, followed by an increased influx of calcium into blood vessel endothelial cells, which further generated NO [33]. NO modulates the transport of nutrients, ions, and then regulates the function of
$\mathrm{BBB}[34,35]$. However, excess production of $\mathrm{NO}$ increases the blood flow and permeability of the BBB allowing substances to enter into the brain passively $[35,36]$. The modulation of NO availability by eNOS seems to be an important determinant to maintain cerebral perfusion in the hypoxia-ischemia condition and reduce the adverse effects caused by hypoxia or ischemia in cerebrum [33].

Our results revealed that the rs2070744 C allele presents a remarkable risk for increasing the susceptibility for HIE in children born full-term and that the $\mathrm{C} / \mathrm{C}$ genotype was significantly linked to poor respiratory function. Based on the pivotal role of the C/C genotype and C allele in rs2070744 in both cardiovascular disorders and HIE, we can infer that this variant in the NOS3 gene promoter might affect eNOS enzyme properties and further reduce the protective effects of NO by affecting NOS3 mRNA expression levels directly. Finally, the imbalance of NO can further lead to an opening of the $\mathrm{BBB}$, eventually leading to secondary brain damage.

In summary, we presented an association analysis between NOS3 gene variants and the susceptibility and symptom expression of HIE and concluded that the NOS3 gene rs2070744 polymorphism could be a potential biomarker for HIE diagnosis and symptoms in a Chinese Han population. However, limitations were also present in this study. For example, the inadequate sample size might lead to false positive or negative results and a slightly lower test power. In contrast, only three NOS3 gene SNPs were selected for the association analysis, and gene-gene or gene-environment interactions have not been taken into consideration. Therefore, further studies with larger sample sizes and more gene variants are needed to completely understand the roles of NOS3 gene variants in the development of HIE.

\section{Conclusions}

The NOS3 gene promoter SNP rs2070744 was significantly associated with HIE susceptibility and its Apgar scores in a Chinese Han population. Therefore, we inferred that rs2070744 could be a potential biomarker for predicting the risks of HIE and asphyxia in this population. 


\section{Abbreviations}

$\begin{array}{ll}\text { HIE: } & \text { Hypoxic-ischemic encephalopathy } \\ \text { BBB: } & \text { Blood-brain barrier } \\ \text { LDL: } & \text { Low-density lipoprotein } \\ \text { VEGF: } & \text { Vascular endothelial growth factor } \\ \text { HWE: } & \text { Hardy-Weinberg equilibrium } \\ \text { MRI: } & \text { Magnetic resonance imaging } \\ \text { NOS: } & \text { Nitric oxide synthase } \\ \text { NOS1/nNOS: } & \text { Neuronal nitric oxide synthase } \\ \text { NOS2/iNOS: } & \text { Inducible nitric oxide synthase } \\ \text { NOS3/eNOS: } & \text { Endothelial nitric oxide synthase } \\ \text { PCR: } & \text { Polymerase chain reaction } \\ \text { SNP: } & \text { Single nucleotide polymorphism. }\end{array}$

\section{Consent}

Written informed consent was obtained from parents.

\section{Competing Interests}

The authors declare that they have no competing interests.

\section{Authors' Contributions}

Yongqin $\mathrm{Wu}$ and Zhiling Zhu designed the study. Yongqin $\mathrm{Wu}$ and Xiaoxia Fang wrote the protocol and the first draft of the manuscript. Yongqin Wu, Xiaoxia Fang, and Ling Yin finished the biological experiments. Yongqin Wu, Yuxia Liu, and Shouxia $\mathrm{Xu}$ undertook the statistical analysis. Yongqin $\mathrm{Wu}$, Zhiling Zhu, and Aixue Li collected clinical samples and data. Yongqin Wu and Xiaoxia Fang managed the literature searches and analyses. All authors contributed to and have approved the final manuscript.

\section{Acknowledgments}

The authors thank Shuai He (Chengdu Fx Biotechnology LLC.), who assisted with the biological experiments and the proofreading of this manuscript.

\section{References}

[1] J. M. Perlman, "Summary proceedings from the neurology group on hypoxic-ischemic encephalopathy," Pediatrics, vol. 117, no. 3, part 2, pp. S28-S33, 2006.

[2] J. J. Volpe, "Neonatal encephalopathy: an inadequate term for hypoxic-ischemic encephalopathy," Annals of Neurology, vol. 72, no. 2, pp. 156-166, 2012.

[3] S. Shankaran, A. R. Laptook, J. E. Tyson et al., "Evolution of encephalopathy during whole body hypothermia for neonatal hypoxic-ischemic encephalopathy," Journal of Pediatrics, vol. 160, no. 4, pp. 567-572.e3, 2012.

[4] S. Shankaran, A. Pappas, S. A. McDonald et al., "Childhood outcomes after hypothermia for neonatal encephalopathy," The New England Journal of Medicine, vol. 366, no. 22, pp. 20852092, 2012.

[5] K. Palsdottir, A. Dagbjartsson, T. Thorkelsson, and H. Hardardottir, "Birth asphyxia and hypoxic ischemic encephalopathy, incidence and obstetric risk factors," Laknabladid, vol. 93, no. 9, pp. 595-601, 2007.

[6] C. Napoli and W. Palinski, "Neurodegenerative diseases: insights into pathogenic mechanisms from atherosclerosis," Neurobiology of Aging, vol. 26, no. 3, pp. 293-302, 2005.

[7] C. Napoli, J. L. Witztum, F. de Nigris, G. Palumbo, F. P. D'Armiento, and W. Palinski, "Intracranial arteries of human fetuses are more resistant to hypercholesterolemia-induced fatty streak formation than extracranial arteries," Circulation, vol. 99, no. 15, pp. 2003-2010, 1999.

[8] K. A. Witt, K. S. Mark, S. Hom, and T. P. Davis, "Effects of hypoxia-reoxygenation on rat blood-brain barrier permeability and tight junctional protein expression," American Journal of Physiology-Heart and Circulatory Physiology, vol. 285, no. 6, pp. H2820-H2831, 2003.

[9] T. S. Reese and M. J. Karnovsky, "Fine structural localization of a blood-brain barrier to exogenous peroxidase," Journal of Cell Biology, vol. 34, no. 1, pp. 207-217, 1967.

[10] A. Kumar, R. Mittal, H. D. Khanna, and S. Basu, "Free radical injury and blood-brain barrier permeability in hypoxicischemic encephalopathy," Pediatrics, vol. 122, no. 3, pp. e722e727, 2008.

[11] R. Pannu and I. Singh, "Pharmacological strategies for the regulation of inducible nitric oxide synthase: neurodegenerative versus neuroprotective mechanisms," Neurochemistry International, vol. 49, no. 2, pp. 170-182, 2006.

[12] L. J. Ignarro, G. Cirino, A. Casini, and C. Napoli, "Nitric oxide as a signaling molecule in the vascular system: an overview," Journal of Cardiovascular Pharmacology, vol. 34, no. 6, pp. 879886, 1999.

[13] R. Popp, I. Fleming, and R. Busse, "Pulsatile stretch in coronary arteries elicits release of endothelium- derived hyperpolarizing factor: a modulator of arterial compliance," Circulation Research, vol. 82, no. 6, pp. 696-703, 1998.

[14] P. A. Marsden A, H. H. Q. Heng, S. W. Scherer et al., "Structure and chromosomal localization of the human constitutive endothelial nitric oxide synthase gene," Journal of Biological Chemistry, vol. 268, no. 23, pp. 17478-17488, 1993.

[15] J. P. Casas, G. L. Cavalleri, L. E. Bautista, L. Smeeth, S. E. Humphries, and A. D. Hingorani, "Endothelial nitric oxide synthase gene polymorphisms and cardiovascular disease: a HuGE review," American Journal of Epidemiology, vol. 164, no. 10, pp. 921-935, 2006.

[16] M. Dahiyat, A. Cumming, C. Harrington et al., "Association between Alzheimer's disease and the NOS3 gene," Annals of Neurology, vol. 46, no. 4, pp. 664-667, 1999.

[17] C.-C. Hong, C. B. Ambrosone, J. Ahn et al., "Genetic variability in iron-related oxidative stress pathways (Nrf2, NQ01, NOS3, and HO-1), iron intake, and risk of postmenopausal breast cancer," Cancer Epidemiology Biomarkers and Prevention, vol. 16, no. 9, pp. 1784-1794, 2007.

[18] R. Medeiros, A. Morais, A. Vasconcelos et al., "Endothelial nitric oxide synthase gene polymorphisms and genetic susceptibility to prostate cancer," European Journal of Cancer Prevention, vol. 11, no. 4, pp. 343-350, 2002.

[19] R. Kuzmanić Šamija, D. Primorac, B. Rešić et al., "Association of NOS3 tag polymorphisms with hypoxic-ischemic encephalopathy," Croatian Medical Journal, vol. 52, no. 3, pp. 396-402, 2011.

[20] R. Kuzmanić Šamija, D. Primorac, B. Resic et al., "Association of NOS3 gene variants and clinical contributors of hypoxicischemic encephalopathy," Brazilian Journal of Medical and Biological Research, vol. 47, no. 10, pp. 869-875, 2014. 
[21] M. Douglas-Escobar and M. D. Weiss, "Hypoxic-ischemic encephalopathy: a review for the clinician," JAMA Pediatrics, vol. 169, no. 4, pp. 397-403, 2015.

[22] V. Benjak, M. Čuljat, M. Pavlović, and M. Kostović-Srzentić, "Changes of the corpus callosum in children who suffered perinatal injury of the periventricular crossroads of pathways," Collegium Antropologicum, vol. 32, Supplement 1, pp. 25-29, 2008.

[23] N. Jovanov-Milošević, M. Čuljat, and I. Kostović, "Growth of the human corpus callosum: modular and laminar morphogenetic zones," Frontiers in Neuroanatomy, vol. 3, article 6, 2009.

[24] Y. Y. Shi and L. He, "SHEsis, a powerful software platform for analyses of linkage disequilibrium, haplotype construction, and genetic association at polymorphism loci," Cell Research, vol. 15, no. 2, pp. 97-98, 2005.

[25] X. Solé, E. Guinó, J. Valls, R. Iniesta, and V. Moreno, "SNPStats: a web tool for the analysis of association studies," Bioinformatics, vol. 22, no. 15, pp. 1928-1929, 2006.

[26] X. Gao, J. Starmer, and E. R. Martin, "A multiple testing correction method for genetic association studies using correlated single nucleotide polymorphisms," Genetic Epidemiology, vol. 32, no. 4, pp. 361-369, 2008.

[27] S. Purcell, S. S. Cherny, and P. C. Sham, "Genetic power calculator: design of linkage and association genetic mapping studies of complex traits," Bioinformatics, vol. 19, no. 1, pp. 149-150, 2003.

[28] Y. Miyamoto, Y. Saito, N. Kajiyama et al., "Endothelial nitric oxide synthase gene is positively associated with essential hypertension," Hypertension, vol. 32, no. 1, pp. 3-8, 1998.

[29] M. Yoshimura, H. Yasue, M. Nakayama et al., "Genetic risk factors for coronary artery spasm: significance of endothelial nitric oxide synthase gene T-786 $\rightarrow \mathrm{C}$ and missense Glu298Asp variants," Journal of Investigative Medicine, vol. 48, no. 5, pp. 367-374, 2000.

[30] D. M. McNamara, R. Holubkov, L. Postava et al., "Effect of the Asp298 variant of endothelial nitric oxide synthase on survival for patients with congestive heart failure," Circulation, vol. 107, no. 12, pp. 1598-1602, 2003.

[31] M. Nakayama, H. Yasue, M. Yoshimura et al., " $T^{-786} \rightarrow C$ mutation in the 5'-flanking region of the endothelial nitric oxide synthase gene is associated with myocardial infarction, especially without coronary organic stenosis," The American Journal of Cardiology, vol. 86, no. 6, pp. 628-634, 2000.

[32] M. E. Hyndman, H. G. Parsons, S. Verma et al., "The T-786 $\rightarrow$ C mutation in endothelial nitric oxide synthase is associated with hypertension," Hypertension, vol. 39, no. 4, pp. 919-922, 2002.

[33] M. A. Moro, A. Cárdenas, O. Hurtado, J. C. Leza, and I. Lizasoain, "Role of nitric oxide after brain ischaemia," Cell Calcium, vol. 36, no. 3-4, pp. 265-275, 2004.

[34] D. Janigro, G. A. West, T.-S. Nguyen, and H. R. Winn, "Regulation of blood-brain barrier endothelial cells by nitric oxide," Circulation Research, vol. 75, no. 3, pp. 528-538, 1994.

[35] C. Kaur and E. A. Ling, "Blood brain barrier in hypoxic-ischemic conditions," Current Neurovascular Research, vol. 5, no. 1, pp. 71-81, 2008.

[36] V. E. Thiel and K. L. Audus, "Nitric oxide and blood-brain barrier integrity," Antioxidants and Redox Signaling, vol. 3, no. 2, pp. 273-278, 2001. 

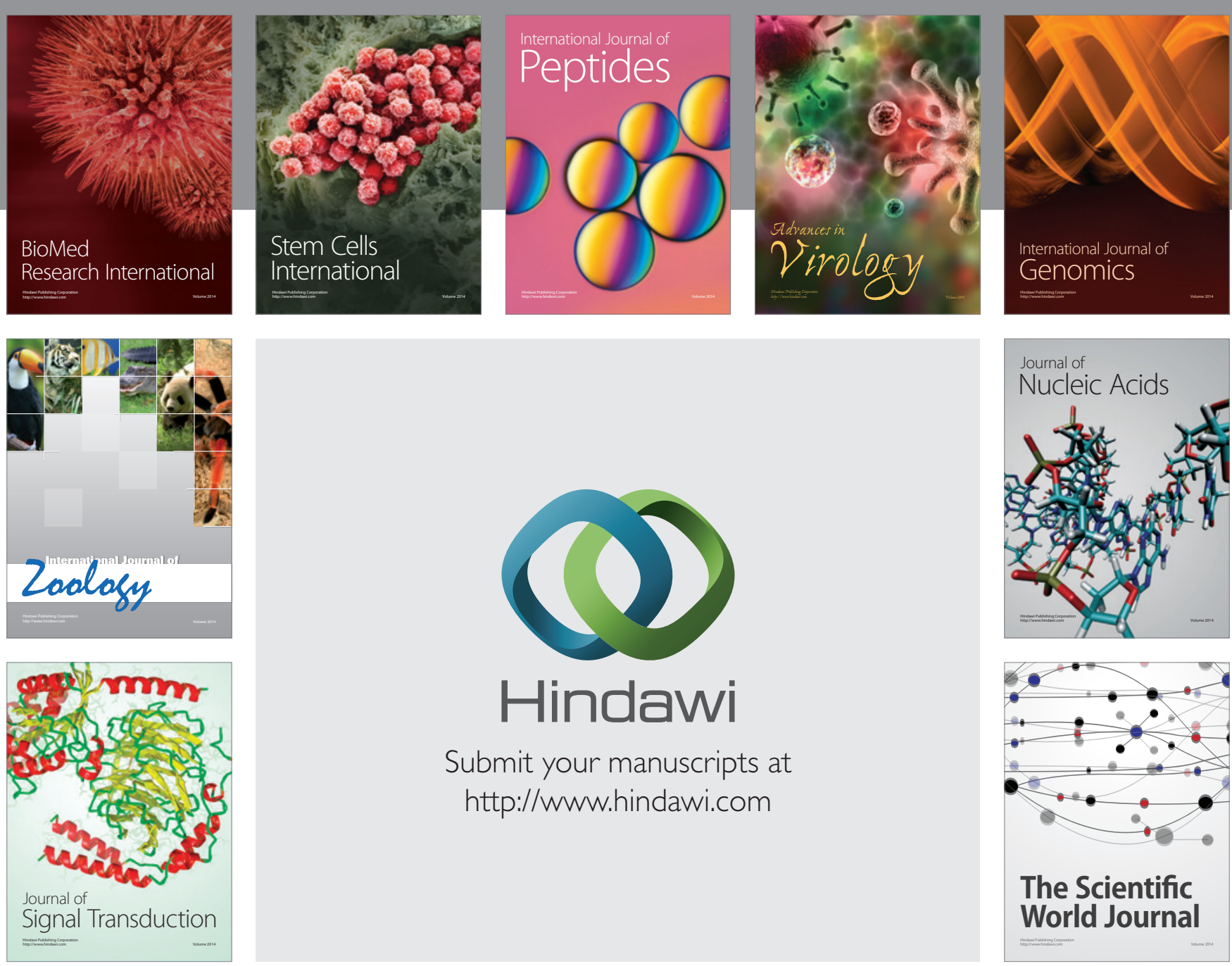

Submit your manuscripts at

http://www.hindawi.com
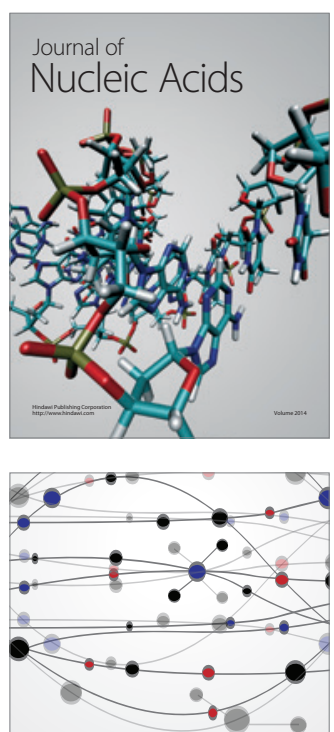

The Scientific World Journal
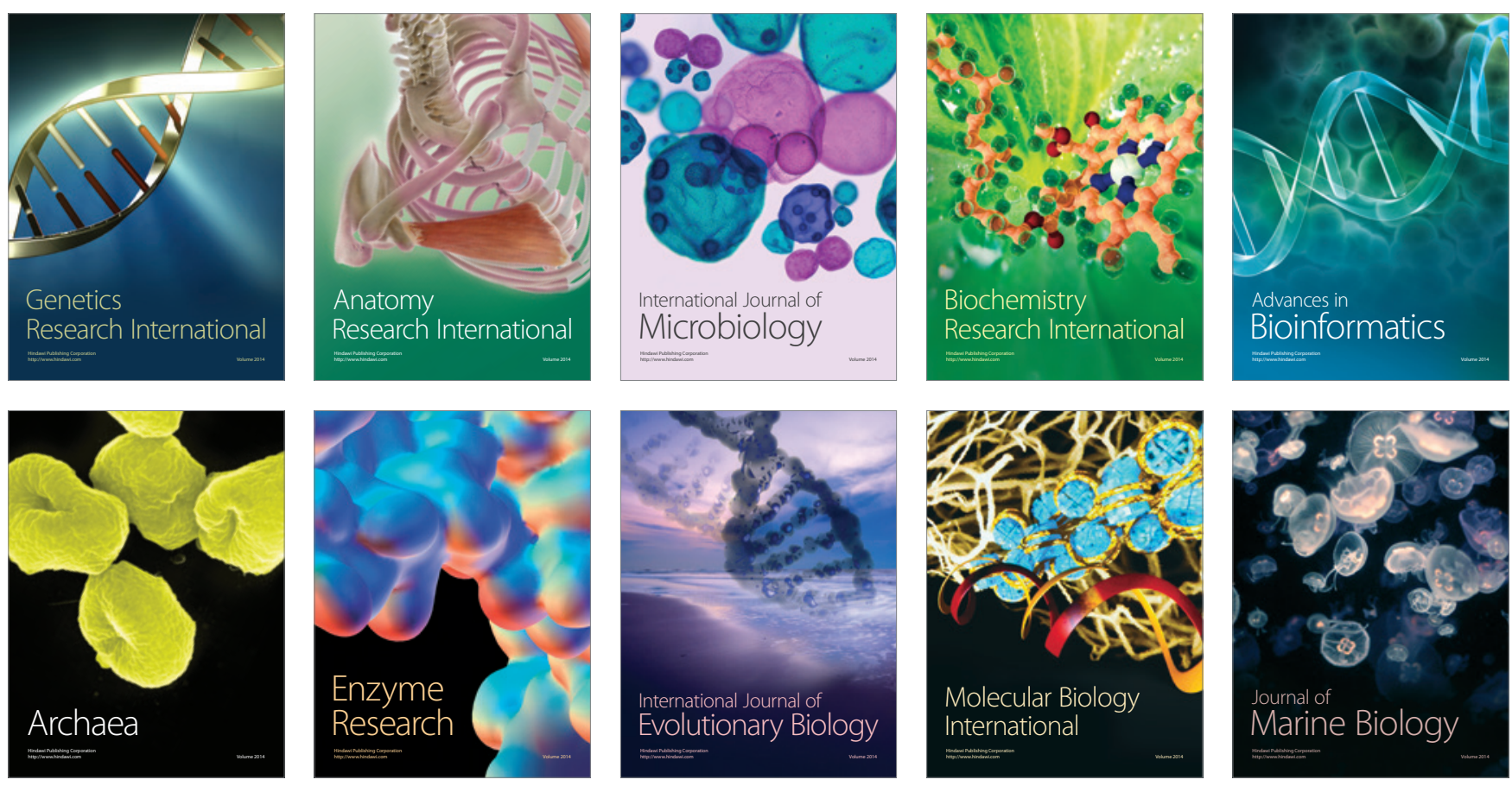